\title{
Capillariid nematodes (Nematoda: Capillariidae) parasitic in the common cormorant (Phalacrocorax carbo), with redescription of Baruscapillaria carbonis (Dubinin et Dubinina, 1940)
}

\author{
Denisa Frantová \\ Institute of Parasitology, Academy of Sciences of the Czech Republic and Department of Parasitology, Faculty of Biological \\ Sciences, University of South Bohemia, Branišovská 31, 37005 České Budějovice, Czech Republic
}

Key words: Baruscapillaria carbonis, Capillariidae, parasitic nematode, common cormorant, Czech Republic

\begin{abstract}
Two species of the genus Baruscapillaria Moravec, 1982 are known to parasitise the small intestine of the common cormorant, Phalacrocorax carbo (L.): Baruscapillaria carbonis (Dubinin et Dubinina, 1940) and B. rudolphii Moravec, Scholz et Našincová, 1994. A redescription of the former species, based on specimens collected from common cormorants shot in South Bohemia, Czech Republic, is provided. Morphological features distinguishing B. carbonis and B. rudolphii are specified. $B$. carbonis is characterised mainly by the well-developed membranous bursa in the male, composed of five distinct lobes (four lateral and one spur-shaped dorsal); the length of the spicule is $1.9-2.3 \mathrm{~mm}$; gravid females are provided with a long vulvar appendage. Males of $B$. rudolphii have reduced, bi-lobed membranous bursa and the spicule is 0.9-1.3 mm long; the vulvar appendage is absent in gravid females. This is the first record of $B$. carbonis in the Czech Republic.
\end{abstract}

Data concerning capillariid nematodes from the common cormorant, Phalacrocorax carbo (L.), is rather scarce. Three species have been reported from this host, all being parasitic in the alimentary tract. Eucoleus contortus (Creplin, 1839) from the oesophagus is most common among waterfowl as well as terrestrial birds around the world (Baruš and Sergeeva 1989). The other two species, both of the genus Baruscapillaria Moravec, 1982, are localised in the small intestine. Until Moravec et al. (1994) described B. rudolphii Moravec, Scholz et Našincová, 1994, all intestinal capillariids found in this host species were referred to Trichosoma carbonis Rudolphi, 1819 (nomen nudum). Moravec et al. (1994) validated B. carbonis, changing its authorship and the date of publication, but they considered it a species inquirenda. The species was reported from a wide range of waterfowl from the Palaearctic Region (for survey see Baruš and Sergeeva 1990), but only a few, inadequate descriptions were provided (Dubinin 1938, Dubinin and Dubinina 1940, Sergeeva 1969, Baruš et al. 1978, Baruš and Sergeeva 1982, Okulewicz 1989, Baruš and Sergeeva 1990).

In 1999, during dissection of two common cormorants from the Czech Republic, capillariid nematodes referable to the species $B$. carbonis (Dubinin et Dubinina, 1940) were found. Their detailed examination made it possible to extend the knowledge of the morphology of this species and its comparison with $B$. rudolphii.

\section{MATERIALS AND METHODS}

A total of two common cormorants, Phalacrocorax carbo, were shot by fishermen at the fishpond system near Chlum $\mathrm{u}$ Třeboně in South Bohemia, Czech Republic, in April 1999. The specimens of $B$. carbonis recovered from the small intestine of one adult female were fixed and stored in $4 \%$ formaldehyde and cleared in glycerine prior to examination. Drawings were made with the aid of a Zeiss microscope drawing attachment. Photographs were made with the aid of an Olympus BX 60 photomicroscope. All measurements are in millimetres, given as the mean (the range in parentheses).

\section{RESULTS}

Baruscapillaria carbonis (Dubinin et Dubinina, 1940)

Figs. 1, 2; Tables 1, 2

Description: Body white, relatively long; males smaller than females. Two distinct lateral bacillary bands extending along almost entire body. Head end narrow, rounded. Muscular oesophagus long; nerve ring situated in first quarter. Neither cervical papillae, nor excretory porus observed. Stichosome composed of single row of stichocytes provided with large nuclei; stichocytes long, subdivided into 7-9 annuli. Two medium-sized, oval or drop-like glandular cells at oesophago-intestinal junction.

Male (12 specimens): Body 14.58 (13.03-16.13) long; width at end of stichosome 0.056 (0.055-0.057). Lateral bacillary bands $0.023(0.018-0.028)$ wide. Nerve ring $0.076(0.063-0.088)$ from anterior end. Entire

Address for correspondence: D. Frantová, Institute of Parasitology, Academy of Sciences of the Czech Republic, Branišovská 31 , 370 05 České Budějovice, Czech Republic. Phone: ++420 38777 5410; Fax: ++420 38 5300388; E-mail: vlkodlak@paru.cas.cz 


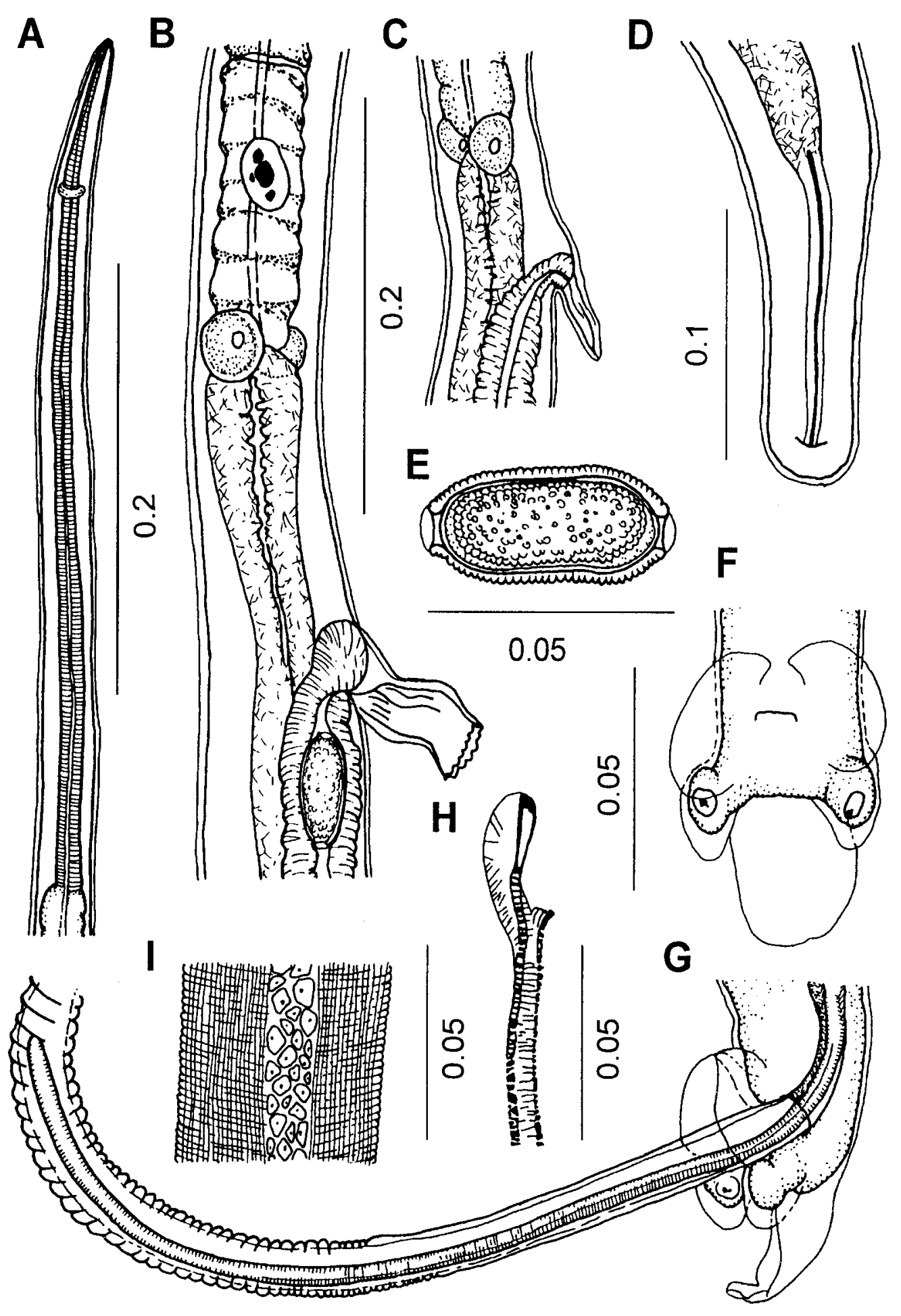

Fig. 1. Baruscapillaria carbonis (Dubinin et Dubinina, 1940). A - anterior end; B, C - vulva region; D - posterior end of female; $\mathbf{E}$ - egg; F, G - caudal end of male, ventral and lateral views with detail of distal end of spicule; $\mathbf{H}$ - proximal end of spicule; I lateral bacillary band. Scale bars in $\mathrm{mm}$. 

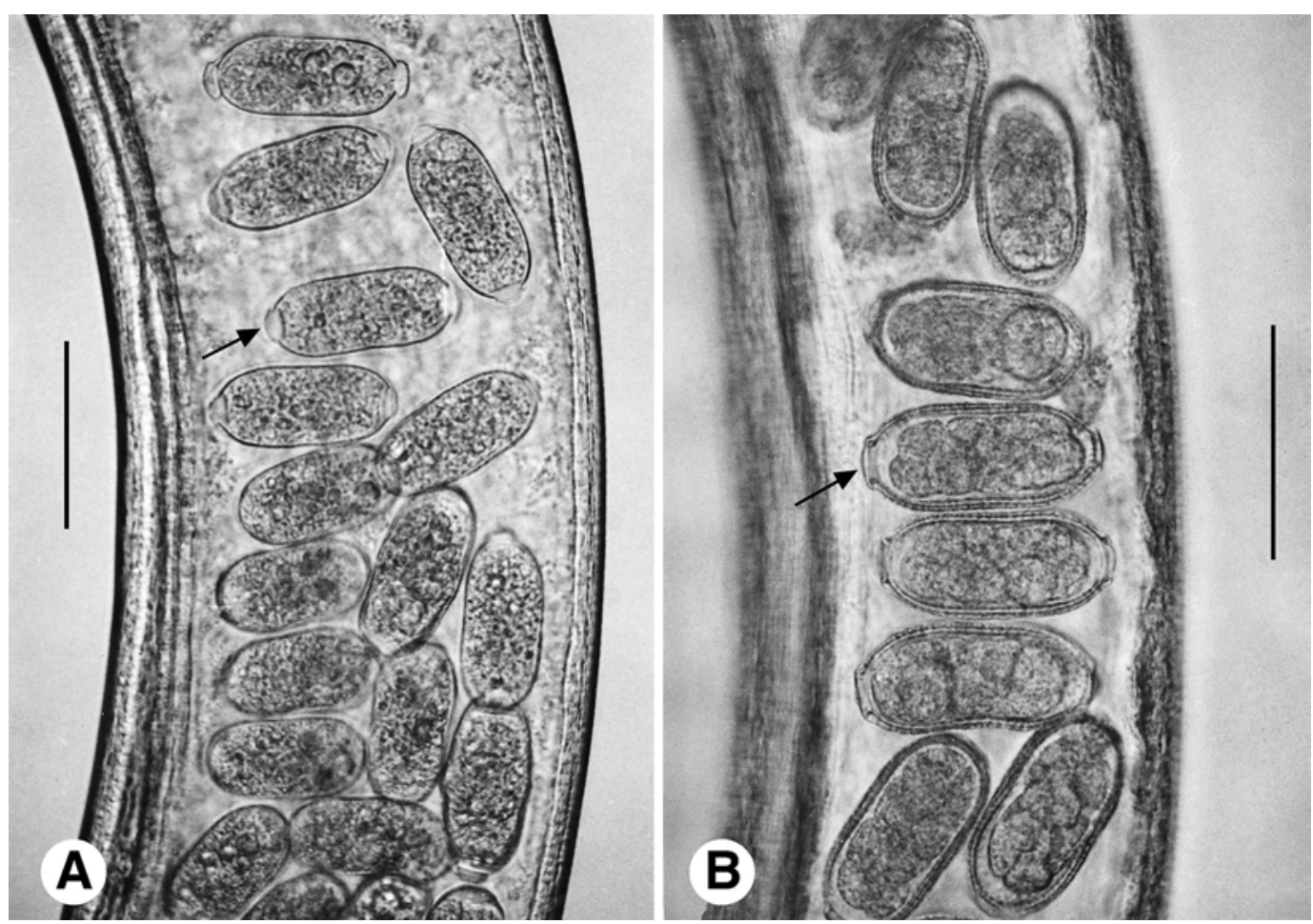

Fig. 2. Baruscapillaria carbonis (Dubinin et Dubinina, 1940), micrographs. A - immature eggs from posterior region of uterus with protruding polar plugs (arrow); B - mature eggs from anterior region of uterus with low polar plugs (arrow). Note the division of the embryos which occurred post mortem (eggs normally laid in the single-cell stage). Scale bars $=0.05 \mathrm{~mm}$.

oesophagus 5.27 (4.67-5.86) long, stichosome 4.84 (4.28-5.40). Stichocytes 47 (43-50) in number, 0.099 (0.085-0.113) long and $0.032 \quad(0.030-0.033)$ wide. Spicule 2.359 (2.286-2.432) long, well sclerotised; its proximal end $0.027 \quad(0.025-0.028)$ wide, bluntly expanded, distal end rounded, 0.005 wide. Spicular sheath without spines. Caudal lateral alae absent. Caudal end with wide and long, well-developed membranous bursa supported by two lateroventral processes; each process with papilla. Bursa 0.064 (0.050-0.078) long, 0.057 (0.050-0.063) wide, composed of five lobes: a dorsal, median one (spur-shaped in lateral view) and two lateroventral semi-oval lobes on either side, beginning anterior to cloacal opening and closely surrounding distal processes. Cloacal opening subterminal.

Female (5 gravid specimens): Body 31.17 (27.4234.91) long; width at end of stichosome $0.079(0.065$ 0.093). Lateral bacillary bands $0.029 \quad(0.028-0.030)$ wide. Nerve ring $0.092(0.076-0.107)$ from anterior end. Entire oesophagus 7.41 (6.91-7.91) long, stichosome 6.87 (6.41-7.32). Stichocytes 47 (43-51) in number, $0.115(0.100-0.130)$ long and $0.048(0.038-0.058)$ wide. Vulva 7.46 (6.97-7.95) from anterior end, $0.110(0.05-$ 0.170 ) posterior to level of oesophago-intestinal junction. Vulvar appendage present in all females, 0.064 (0.050-0.078) long and $0.022(0.013-0.030)$ wide, sometimes shrunken and indistinct. Eggs oval, thickwalled, 0.054 (0.050-0.058) long and 0.024 (0.0230.025 ) wide, with distinct granular structure on surface. Polar plugs protrude in immature eggs; slight protrusion visible in fully mature eggs. Content of mature eggs uncleaved. Posterior extremity tapered and rounded. Anus subterminal.

H o s t : Phalacrocorax carbo (L.) (Phalacrocoracidae, Pelecaniformes).

$S$ i t e : Small intestine.

P r e v a 1 e $\mathrm{n}$ c e : One infected out of 2 adult cormorants examined; intensity 17 specimens per bird.

L o c a 1 i t y : Novořecké močály near Chlum u Třeboně,

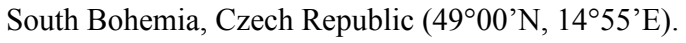

$\mathrm{S}$ p e c i m e n s : Deposited in Helminthological Collection of the Institute of Parasitology, Academy of Sciences of the Czech Republic (ASCR), in České Budějovice (Cat. No. N768).

\section{Key to the capillariid nematodes parasitic in Phal- acrocorax carbo}

1 Parasites of oesophagus; spicular sheath spiny; spicule slender, weakly sclerotised

Eucoleus contortus

- Parasites of small intestine; spicular sheath nonspiny; spicule well sclerotised 2 
Table 1. Dimensions (in mm) of male Baruscapillaria carbonis and B. rudolphii from the common cormorant, Phalacrocorax carbo; original measurements given as the mean (the range in parentheses).

\begin{tabular}{|c|c|c|c|c|c|}
\hline \multirow{2}{*}{$\begin{array}{l}\text { Species } \\
\text { Author }\end{array}$} & \multicolumn{2}{|c|}{ B. rudolphii } & \multicolumn{3}{|c|}{ B. carbonis } \\
\hline & $\begin{array}{l}\text { Moravec et al. } \\
\text { (1994) }\end{array}$ & $\begin{array}{c}\text { Baruš and } \\
\text { Sergeeva (1990) }\end{array}$ & $\begin{array}{c}\text { Dubinin and } \\
\text { Dubinina (1940) }\end{array}$ & $\begin{array}{c}\text { Okulewicz } \\
\text { (1989) }\end{array}$ & Present study \\
\hline Number of specimens & 1 & 6 & - & 2 & 12 \\
\hline Length of body & 11.82 & $8.3-10.7$ & 13.0 & $14.58-15.38$ & $\begin{array}{c}14.58 \\
(13.02-16.13) \\
\end{array}$ \\
\hline Width of body & 0.068 & $0.047-0.062$ & 0.075 & $0.060-0.066$ & $\begin{array}{c}0.056 \\
(0.055-0.057)\end{array}$ \\
\hline Width of lateral bacillary bands & 0.012 & $0.020-0.025$ & - & $0.012-0.014$ & $\begin{array}{c}0.023 \\
(0.018-0.028)\end{array}$ \\
\hline Anterior - nerve ring & 0.087 & - & - & $0.083-0.086$ & $\begin{array}{c}0.076 \\
(0.063-0.088)\end{array}$ \\
\hline Length of entire oesophagus & 5.99 & $4.81-6.43$ & - & $5.16-5.56$ & $\begin{array}{c}5.27 \\
(4.67-5.86) \\
\end{array}$ \\
\hline Length of stichosome & 5.72 & $4.5-6.0$ & - & - & $\begin{array}{c}4.84 \\
(4.28-5.40) \\
\end{array}$ \\
\hline $\begin{array}{ll}\text { Stichocytes: } & \text { length } \\
& \text { width }\end{array}$ & - & - & - & - & $\begin{array}{c}0.099 \\
(0.085-0.113) \\
0.032 \\
(0.030-0.033) \\
\end{array}$ \\
\hline Number of stichocytes & - & $35-39$ & - & $38-42$ & $\begin{array}{c}47 \\
(43-50)\end{array}$ \\
\hline Length of spicule & 1.25 & $0.85-1.10$ & - & $1.94-2.03$ & $\begin{array}{c}2.359 \\
(2.286-2.432)\end{array}$ \\
\hline Width of proximal end of spicule & 0.018 & $0.020-0.030$ & 0.015 & $0.013-0.014$ & $\begin{array}{c}0.027 \\
(0.025-0.028)\end{array}$ \\
\hline Width of distal end of spicule & - & $0.004-0.005$ & 0.005 & 0.004 & 0.005 \\
\hline $\begin{array}{l}\text { length } \\
\text { width }\end{array}$ & - & $\begin{array}{l}0.025-0.027 \\
0.016-0.018\end{array}$ & - & - & $\begin{array}{c}0.064 \\
(0.050-0.078) \\
0.057 \\
(0.050-0.063)\end{array}$ \\
\hline
\end{tabular}

2 Membranous bursa of male well developed, composed of five distinct lobes; spicule 1.9-2.3 mm long; gravid females with tubular vulvar appendage . Baruscapillaria carbonis

- Membranous bursa of male reduced, composed of two lateral lobes; spicule 0.9-1.3 mm long; gravid females without vulvar appendage

\section{Baruscapillaria rudolphii}

\section{DISCUSSION}

Trichosoma carbonis (= Baruscapillaria carbonis), recovered from the intestine of Phalacrocorax carbo from Vienna, was first mentioned by Rudolphi (1819). Since he gave no description, it was considered a nomen nudum for many years. The first recognisable description and illustrations were provided by Dubinin and Dubinina (1940), based on the nematodes recovered from Plegadis falcinellus (L.) of the Volga Delta in Russia. Thus, Moravec et al. (1994) validated this species with the authorship and the year of publication of the latter authors. The main morphological feature given by Dubinin and Dubinina (1940) was the large membranous bursa of male, composed of four lobes: an anterior, discoid one, a large posterior one in the shape of a sharp projection and two lateral. A four-lobed bursa was reported also by Baruš et al. (1978) and Okulewicz (1989). The detailed examination of the male caudal end in the present study showed no sign of an anterior discoid lobe (Fig. 1F, G); the bursa consisted of five lobes: a spur-shaped dorsal one and two lateral on each side, this being the most prominent morphological feature, distinguishing the males of $B$. carbonis and $B$. rudolphii. The male bursa of $B$. rudolphii is reduced and bi-lobed (Moravec et al. 1994).

Dubinin and Dubinina (1940) did not give the length of spicule. Comparing the measurements of the present study with those of Okulewicz (1989), Baruš and Sergeeva (1990) and Moravec et al. (1994) (Table 1), all based on specimens from $\mathrm{Ph}$. carbo, it is obvious that the spicule of $B$. carbonis is distinctly longer (1.9-2.3) than that of B. rudolphii (maximum 1.3). Baruš and Sergeeva (1990) gave the length of spicule 0.85-1.10; they also described the membranous bursa of male as reduced and bi-lobed and, therefore, Moravec et al. (1994) considered their specimens to be similar to and possibly conspecific with B. rudolphii. 
Table 2. Dimensions (in mm) of female Baruscapillaria carbonis and B. rudolphii from the common cormorant, Phalacrocorax carbo; original measurements given as the mean (the range in parentheses).

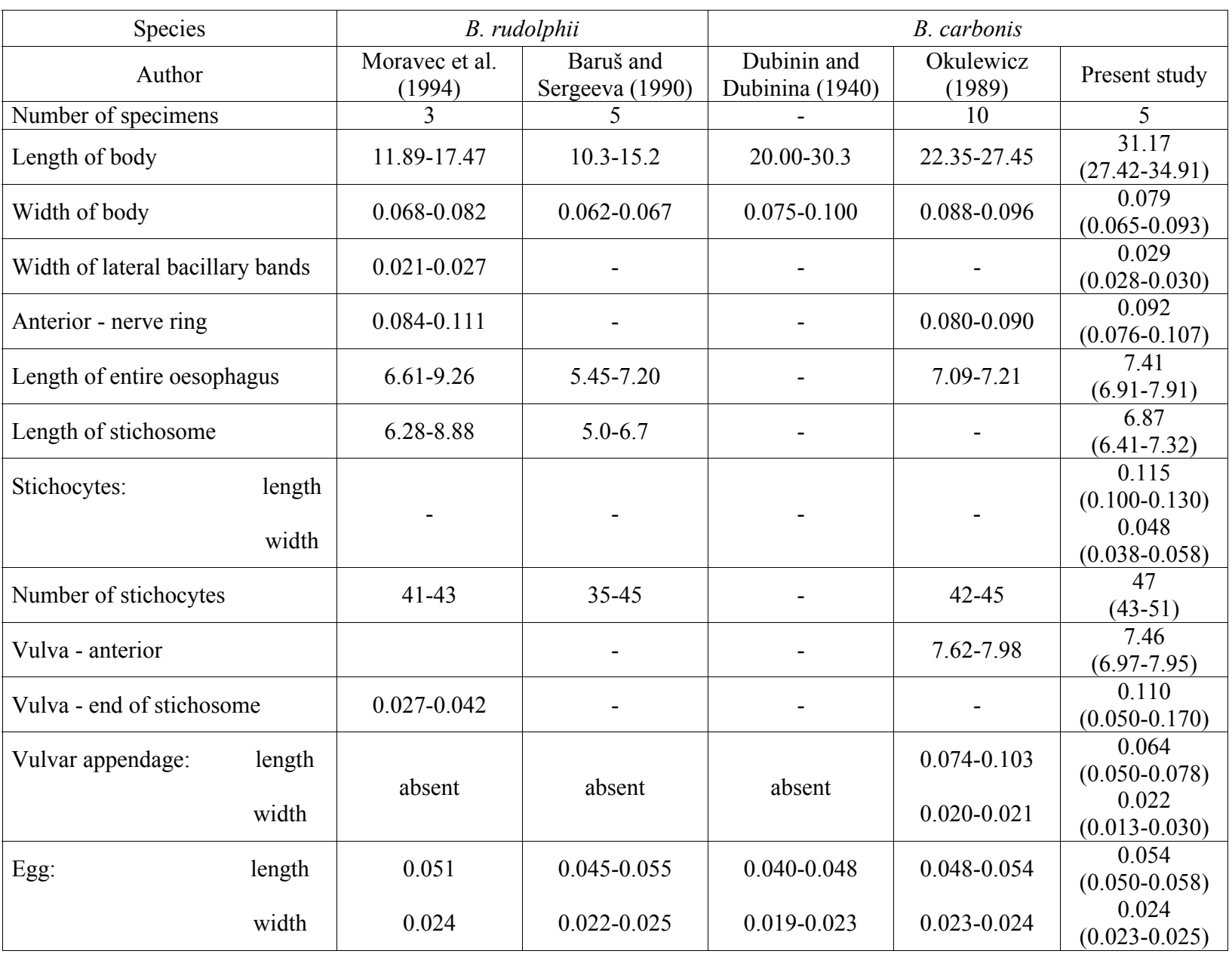

The descriptions of female specimens of B. carbonis by Dubinin (1938) and Dubinin and Dubinina (1940) were inadequate and no drawings were given. They did not mention either the position of the vulva or the structure of the vulva region. In the present study, all the gravid females had a vulvar appendage (Table 2, Fig. $1 \mathrm{~B}, \mathrm{C})$ which was shrunken and poorly visible in a few cases. Okulewicz (1989) stated the presence of a vulvar appendage in three of ten gravid females. It may well be that the absence of a vulvar appendage in some females was influenced, for example, by the method of fixation. The purpose of this structure is still unknown. Sergeeva (1979) experimentally proved the development of a vulvar appendage at the age of egg formation; it was absent in young females. With respect to the fact that vulvar appendage was completely absent in all female B. rudolphii examined by Baruš and Sergeeva (1990) and Moravec et al. (1994), the presence or absence of this structure should be considered an additional morphological feature distinguishing $B$. carbonis and $B$. rudolphii.
Other previous descriptions of B. carbonis (Rudolphi, 1819) are based on specimens originating from birds other than cormorant: Larus genei (Sergeeva 1969), various waterfowl including Phalacrocorax carbo (Baruš et al. 1978) and Sterna hirundo, Pluvialis apricaria and P. squatarola (Baruš and Sergeeva 1982). Baruš et al. (1978) described the membranous bursa of male as four-lobed, although there is no dorsal lobe seen in the accompanying drawing (cited from Sergeeva 1969). The measurements of the spicule (0.85-1.10) and the body length are more consistent with those given for B. rudolphii. Similarly, morphological and metrical data given by Baruš and Sergeeva (1982), i.e., a small, reduced bursa, the spicule 1.16-1.41 long and the absence of a vulvar appendage, are more likened to B. rudolphii than B. carbonis.

On the basis of the results presented here, it is possible to accurately distinguish two congeneric nematodes parasitic in cormorants. $B$. carbonis may be distinguished from $B$. rudolphii by a five-lobed bursa 
and a long (1.9-2.3) spicule of the male and the possible presence of a vulvar appendage of the female.

The biology of both B. carbonis and B. rudolphii is completely unknown but, with respect to the fact that all of the reported hosts are piscivorous, fish probably play some role in the development or the transmission of these parasites. Both species have been found in Europe several times (see Baruš and Sergeeva 1990, Moravec et al. 1994), though this is the first occurrence of $B$. carbonis in the Czech Republic.

Acknowledgements. The author thanks Dr. F. Moravec of the Institute of Parasitology, Academy of Sciences of the Czech Republic for his valuable advice and critical comments and $\mathrm{H}$. Splittgerber for grammatical corrections.

\section{REFERENCES}

BARUŠ V., SERGEEVA T.P. 1982: On the capillariid fauna (Nematoda) of birds from the Lower $\mathrm{Ob}$ River. Helminthologia 19: 97-106.

BARUŠ V., SERGEEVA T.P. 1989: Capillariids parasitic in birds in the Palaearctic Region 2. Genera Eucoleus and Echinocoleus. Acta Sci. Nat. Brno 23: 1-47.

BARUŠ V., SERGEEVA T.P. 1990: Capillariids parasitic in birds in the Palaearctic Region 3. Genus Baruscapillaria. Acta Sci. Nat. Brno 24: 1-53.

BARUŠ V., SERGEEVA T.P., SONIN M.D., RYZHIKOV K.M. 1978: Helminths of fish-eating birds of the Palaearctic Region. I. Nematoda. Academia, Praha, 318 pp.

DUBININ V.B. 1938: Changes in the parasite fauna of glossy ibis (Plegadis falcinellus) caused by the growth and migration of the host. Tr. Astrakh. Gos. Zapov. 2: 114212. (In Russian.)

DUBININ V.B., DUBININA M.N. 1940: Parasite fauna of bird colonies of the Astrakhan Reserve. Tr. Astrakh. Gos. Zapov. 3: 190-298. (In Russian.)
MORAVEC F., SCHOLZ T., NAŠINCOVÁ V. 1994: The systematic status of Trichosoma carbonis Rudolphi, 1819 and a description of Baruscapillaria rudolphii n. sp. (Nematoda: Capillariidae), an intestinal parasite of cormorants. Syst. Parasitol. 28: 153-158.

OKULEWICZ A. 1989: Redescription of Capillaria carbonis (Rudolphi, 1819) (Capillariidae) based on material collected from the cormorant (Phalacrocorax carbo). Wiad. Parazytol. 35: 577-583.

RUDOLPHI C.A. 1819: Entozoorum synopsis cui accedunt mantissa duplex et indices locupletissimi. S.A. Rücker, Berolini, $811 \mathrm{pp}$.

SERGEEVA T.P. 1969: Nematode fauna of gulls in the USSR. Tr. GELAN 20: 146-155. (In Russian.)

SERGEEVA T.P. 1979: Vulvar appendage in capillariids as a diagnostic feature. Tr. GELAN 33: 135-143. (In Russian.)

Accepted 10 January 2001 